\title{
Research on the Innovation of Corporate Marketing Strategy
}

\author{
Wei Jin \\ Guizhou University of Finance and Economics, Guiyang, Guizhou, China, 550004
}

Keywords: enterprise; marketing; strategic innovation

\begin{abstract}
With the increasing growth of science and technology, market economy has gradually been one of the valued concern of our country. Nowadays the traditional market economy has transferred from the early seller's economy to the current buyer's economy. Based on the background, enterprise itself should pay more attention to the marketing and continuously innovate the initial strategy based on the practical situation of market, which can lead to the higher economic benefit. This paper herein demonstrates the basic meaning of marketing strategy, analyzes the current situation of market strategic innovation and then proposes some reasonable opinions on detailed improvement schemes.
\end{abstract}

\section{Introduction}

As far as the current development is concerned, the competition between enterprises has been changing and gradually transferring to the level of strategic competition. So only with meeting the basic needs of consumers can enterprise grasp the entire changing trend of market. It is the reason that enterprises should make innovation on the strategic level.

\section{Crucial Meaning of Marketing Strategy}

Nowadays the market of our country has been increasingly perfect, so enterprises may face with totally new situation. Especially after the growing improvement of the opening up, more and more foreign enterprises can directly come into the market of our country and take part in the competition. Considering the situation, enterprises of our country need to develop innovative strategy in order to meet the needs of the basic demands of the market of our country and open up the international market at the same time, which will finally promote the development of the entire industry.

Therefore, under the background of the fierce competition, enterprises have to improve and optimize on the level of marketing strategy for having a head start and winning abundant economic benefit, which may trigger the pragmatic and positive development for enterprises themselves. Talking about the part of positive development, it refers to knowing the basic needs of each level of customers in the market while the pragmatic one refers to being capable of constructing sound marketing sense and improving the service quality on the basis of marketing sense to stimulate the whole enterprise to break out in the future market ${ }^{[1]}$.

\section{Practical Situation of Current Market Strategic Innovation}

\subsection{Lack of marketing sense}

As far as the current situation is concerned, enterprises of our country still haven't paid enough attention on marketing strategy and most of the administrators themselves don't realize the importance of marketing strategy. As a result, they still produce products according to their working experience, which apparently shows the production is so isolated that it doesn't combine with the current situation of market economy and the analysis of market is also one-sided. From an objective perspective, it is the opposite to the market economy subject that leads to the decrease of economic benefit of enterprises. 


\subsection{Lack of market research}

Except for the lack of emphasis on marketing strategy, one of the other problem that enterprises of our country have is the lack of attention on the current market conditions, which is to say, most of the marketing activities still target at the consumers themselves but lack the enough knowing of the principle issues. The reason is that the cost of market research is high and most of enterprises may cut the cost input for the economic benefit, which may finally cause the situation that the final products may not conform to what is expected. Finally, instead of gaining benefit, the development of enterprises is further influenced ${ }^{[2]}$.

\subsection{Laggard marketing concept}

In current economic activities in the market, the reason why enterprises have no need to transfer their marketing strategy is because the market is always changed passively. Therefore, executives of enterprises need to continuously innovative their own concepts based on the demands of market. However, some of executives have a rather narrow view about the understanding of market and lay emphasis only on the pursue of economic benefit and market trend instead of combining their own characteristics, which may eventually lead to the development of enterprises constrained by external conditions.

\section{Detailed Scheme of the Innovation of Marketing Strategy}

\subsection{Improve the corporate strategy}

The innovation of corporate marketing should not innovate unilaterally in the work but do it from the strategic point of view. Enterprise, as the essential participant, should equip with the value of subjective initiative in some extent which may always present depending on the development strategy of enterprise. So, corporate marketing should start from integrality, which means they should make plans for business pattern, scale of production and marketing approach in advance. Thus, enterprises may practically understand what they need to do and how they can do from the perspective of themselves, which can further lay the sound foundation for the potential development of enterprises.

From the perspective of corporate marketing, marketing strategy may mainly refer to the detailed types, market positioning and marketing concepts of the ultimate products. Only by solving all these problems in the process of practical development can enterprises ensure that the effect of marketing concepts has produced its best results.

\subsection{Improve operating efficiency}

During the process of the development of enterprises, marketing activities can be regarded as subjects and product quality is the foundation of any of the activities. Marketing and quality are connected to each other and there is no contradiction. If there occur any problems in each link, then the economic development of the entire enterprise will be badly influenced. Therefore, enterprises have to lay emphasis on the two aspects. Enterprises need to improve their management style and business pattern, such as updating equipment, business combination and enterprise outsourcing, which can help ensure the plenty number of products to meet the needs of the market and enhance customer satisfaction. When talking about the quality of products, enterprises need to keep the positive attitude all the time for the needs of market are changing dynamically. And it is essential to draw up related quality mechanism in advance in order to ensure the quality of products can conform to what they are expected to be ${ }^{[3]}$.

\subsection{Dig potential needs of the market}

Nowadays, with the increasingly fierce market competition, market differentiation is gradually serious, which means part of enterprises will enjoy certain advantages that may bring some constraint to some enterprises that come to the market late. Especially in the new period that the market is on the way of perfection, many advantageous enterprises will apply for patent protection 
in advance, which leaves high threshold to enterprises that come to the market late. In order to find inroad into the market, these enterprises have to pay higher cost of funds. Considering the situation, enterprises can't blindly follow the trend and lay their emphasis only on the market segment that seems to produce high economic benefit superficially. And what they should do is pay more attention to the industry itself, continuously dig the potential needs of the market and conduct more targeted marketing activities, which can finally bring higher economic benefit to enterprises.

\subsection{Establish proper marketing pattern}

The choice of marketing pattern is an important task which should be started from the strategic perspective of an enterprise combining the current state of operation. Thus, an enterprise can draw up its own unique marketing pattern. Not only that, marketing pattern of an enterprise should conform to its productivity, which can ensure the success of marketing strategy. Moreover, marketing pattern also needs to conform to the product of an enterprise. Nowadays, per capita income of our country has been increasing, which triggers two features of people's consuming behavior. One is the continuous growth of consumer demands and the other is the higher requirement for quality of consumption, especially for some younger groups who pursue the personalized consumption. So, the products of an enterprise should value this kind of demand and conduct related marketing activities, which can help open up the potential market and promise more economic benefit for an enterprise.

\section{Conclusion}

As all mentioned above, in the current market environment, corporate marketing has been more and more important. Thus, an enterprise should improve its operation philosophy, perfect business pattern and lay more emphasis on marketing strategy based on the market situation to enhance the growth of the industry.

\section{References}

[1] Tang Lixiang. Research on Marketing Strategy Innovation of Enterprises [J]. Journal of Chifeng College (Natural Edition: 125-126).

[2] Kang Dezhi. Research on Marketing Strategy Innovation of Enterprises [J]. Engineering Technology: abstract Edition 2015 / 8: 00080-00080.

[3] Li Guang. Research on Marketing Strategy Innovation of Enterprises [J]. Modern Marketing (next issue: 72-72). 